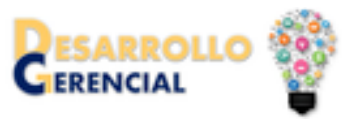

\section{Empresariado de Sincelejo: Almacén Leo, del éxito a la sobrevivencia empresarial}

\author{
Sincelejo's entrepreneurship: Almacen Leo, from success \\ to business survival
}

Aylin Patricia Pértuz Martínez

Universidad de Sucre, Sincelejo, Colombia.

Francia Helena Prieto Baldovino

Universidad del Sinú, Montería, Colombia.

Wilson Guzmán Cadrazco Parra iD

Universidad de Sucre, Sincelejo, Colombia.

\title{
Resumen
}

Objetivo: Describir e interpretar el desarrollo de la empresa Almacén Leo de la ciudad de Sincelejo, desde 1960 hasta 2019. Método: la investigación fue cualitativa, analítica e histórica. Las fuentes fueron primarias y para la recolección de la información se utilizó principalmente la entrevista no estructurada. Resultados: En Sincelejo se estableció el Almacén Leo, siendo uno de los almacenes tradicionales de la ciudad. El empresario Leonel González Anaya fue su gestor y administrador de forma ininterrumpida. La empresa desarrolló estrategias para mantenerse en el mercado, pero factores externos e internos impactaron su actividad. Tuvo momentos de éxito, pero los períodos de crisis fueron extensos. Discusiones: Leonel González Anaya fue un empresario y un pionero, no solamente un capitalista. El almacén afrontó riesgos e incertidumbre y la continuidad de la empresa depende de una segunda generación no educada para su gerencia. Conclusiones: La empresa ha tenido éxitos, pero en el siglo XXI, las crisis han sido casi permanentes por factores económicos, la alta competencia, los planes gubernamentales, y por factores internos como su gerencia conservadora, entre otros. Sus estrategias buscaron mantenerse en el mercado, pero se convirtieron en status quo.

Palabras clave: Almacén Leo, Empresario, Sincelejo.

Clasificación JEL: M.

\section{Abstract}

\section{Autores de Correspondencia}

aylin.pertuz@unisucre.edu.co franciaprieto@unisinu.edu.co wilson.cadrazco@unisucre.edu.co

Recibido: 04-09-2019

Aceptado: 17-12-2019

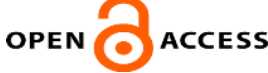

(cc) BY

Copyright (C) 2020

Desarrollo Gerencial
Objective: to describe and interpret Leo Almacen growth at Sincelejo City, from 1960 to 2019. Method: This research is qualitative, historical, and analytical type, and uses first-hand sources, mainly, under techniques such as an unstructured interview. Results: Sincelejo City established Leo Store, is one of the traditional stores of the city. The sir Leonel González Anaya has been the manager and administrator of this store for always. This firm has developed strategies to stay in the market, but external and internal context factors have impacted its activity. In more than fifty years of existence, it has had moments of success, but the periods of the crisis have been long extensive. Discussions: Leonel González Anaya was an entrepreneur and a pioneer, not just a capitalist. Leo Store development had a period of uncertainty and risk, and the company's continuity depends on a secondgeneration not educated for its management. Conclusion: The company has been successful, but in the 21st century, the crises have been almost permanent due to economic factors, high competition, government plans, and internal factors such as its conservative management, among other ones. Their strategies sought to remain in the market, but they became a status quo.

Key words: Leo Almacen, businessman, Sincelejo.

JEL Classification: $M$.

Como citar este artículo (Apa):

Pértuz, A., Prieto, F. y Cadrazco, W. (2020). Empresariado de Sincelejo: Almacén Leo, del éxito a la sobrevivencia empresarial . Desarrollo Gerencial, 12(1), 1-25. DOI: https://doi.org/10.17081/dege.12.1.3591 


\section{Introducción}

La ciudad de Sincelejo fue constituida como capital del departamento de Sucre en el año 1966, y sus inicios se remontan a su fundación en 1775 por Antonio de la Torre y Miranda. Segúnz la Cámara de Comercio de Sincelejo (2017), la economía del departamento de Sucre, ha sido básicamente agropecuaria, pero en el Producto Interno Bruto [PIB] del departamento, este sector perdió dinamismo al pasar del siglo XX al siglo XXI. Así, según el Programa de las Naciones Unidas para el Desarrollo, la Corporación Universitaria del Caribe y el Programa Nacional de Desarrollo Humano (2007) en el lapso de tiempo de 1990 a 2002, el PIB del departamento participó en un 0,8\% del total del país; respecto a la costa Caribe, en 1990 la participación fue del 5,2\%, y en el año 2002, bajó a 5,0\%, siendo el más pobre del Caribe. De acuerdo con la Cámara de Comercio de Sincelejo en el 2017, la participación en la estructura del PIB de Sucre fue de la siguiente manera: 12,8\% del sector agropecuario, 33,3\% de servicios sociales, comunales y personales y $8,6 \%$ del sector comercio y reparación.

Así pues, varias de las empresas que se constituyeron en los años cincuenta y sesenta han perdurado hasta el siglo XXI, pero la comunidad desconoce las formas de cómo han administrado sus recursos y cuál ha sido su actuación frente al entorno, como es el caso del Almacén Leo. La no sistematización de la historia de una empresa reconocida puede deberse al desinterés en estos temas por parte de los empresarios y de los gremios económicos, así como de instituciones públicas y privadas. Asimismo, a la cultura sabanera, que es más de tradición oral que escrita.

En este sentido, este estudio tuvo como objetivo principal describir e interpretar las actividades gerenciales del empresario y el desarrollo que tuvo la empresa Almacén Leo desde el año 1960 hasta el 2019. Como objetivos específicos se establecieron: caracterizar las actividades económicas de la empresa; establecer sus momentos de éxitos y de crisis; determinar los factores internos y externos que han influido en el desarrollo de la misma; identificar las estrategias utilizadas en la empresa para hacerle frente a las oportunidades y amenazas; identificar a los empresarios del almacén; caracterizar la gerencia del empresario y establecer su estilo de riesgo.

El producto de esta investigación beneficiará al empresariado de la región, puesto que es un antecedente que les permitirá obtener mayor información para decisiones efectivas; se constituye en un material bibliográfico para instituciones universitarias; y a partir de ella, se pueden realizar o desprenderse otras investigaciones acerca del empresariado sucreño.

Entre los antecedentes de la investigación, acerca del empresariado del departamento de Sucre y su capital Sincelejo están, entre otras, las publicaciones de Viloria (2001) respecto a los ganaderos de Sincelejo a finales y principios del siglo XX; Támara (1997) acerca de la evolución de la región desde los zenúes hasta el Packing House de Coveñas; Pértuz (2006, 2008, 2015) en cuanto al empresariado de la 
Aylin Pértuz Martínez, Francia Prieto Baldovino, Wilson Guzmán Cadrazco Parra

ciudad; Paternina (2002) en relación con los hechos y personalidades sincelejanas; Aguilera (2005) en cuanto a la economía del departamento y la ganadería; y Fals (2002), quien se ocupa de los empresarios de finales del siglo XIX y principios del siglo XX.

\section{Fundamentación teórica}

La empresa es una entidad compleja; no es lo mismo que el empresario puro, sino que es lo que resulta después que el empresario ha llevado a cabo una decisión empresarial, "específicamente la compra de determinados recursos". (Kirzner, 2007, p. 121)

Autores como Chiavenato (2011), sostienen que las empresas son productoras de bienes y servicios, que brindan empleo a las personas, manejan tecnologías, requieren de recursos y una administración. Se diferencian de otras organizaciones debido a las siguientes consideraciones: están encauzadas a las ganancias, asumen riesgos, son conducidas por una filosofía de negocios; se evalúan desde una perspectiva contable; son identificadas como negocios por sus similares y por las instituciones gubernamentales; se constituyen en propiedad privada. Asimismo, Caldas, Reyes y Heras (2009) señalan que la empresa es una unidad económica que, combinando de forma organizada los diferentes factores materiales y humanos, produce bienes o servicios con el fin de obtener una utilidad económica. Hernández (2011), afirma que la empresa es una organización con una duración más o menos larga, la cual tiene como objetivos tener un beneficio, por medio de la satisfacción de una necesidad en el mercado; en la que se concreta el ofrecimiento de productos ya sea en el sector primario, secundario o terciario de la economía; teniendo como contraprestación un precio o valor económico. Fernández y Campiña (2010) sustentan que la empresa es un conjunto de actividades realizadas por el empresario para la producción e intercambio de bienes y servicios con la finalidad de obtener un máximo beneficio o que le satisfaga.

Por otro lado, Wernerfelt (1984) desde los recursos y capacidades, analiza a la empresa como un conjunto más amplio de recursos que busca tener el equilibrio de la explotación de ellos y el desarrollo de otros nuevos. Helfat y Peteraf (2009) manifiesta que los recursos se pueden clasificar en financieros, físicos, tecnológicos, organizacionales, humanos, conocimiento, de experiencias del equipo de gestión y de servicio al cliente, entre otros. Como indican Nicolás y Rubio (2014), cuando el empresario decide constituir una empresa uno de los primeros retos que debe enfrentar es la gestión de los recursos de que dispone en una forma eficiente.

Dentro de la tipología de la empresa se encuentra la empresa familiar, la cual es considerada generalmente, según Aguilar y Ocampo (2018), como aquella organización cuyo capital está bajo el control de una familia y por lo menos, dos integrantes de la familia hacen parte activa de la gerencia o de las actividades concernientes a la operación, o están en el consejo directivo. 
De acuerdo con Lozano (2003), las relaciones intrafamiliares pueden clasificarse desde la consanguinidad y desde la afinidad. Por lo que los miembros del grupo familiar propietario de la empresa se relacionan con empleados, banqueros, proveedores, clientes y otros accionistas que no son empleados, y así mismo con los miembros de la familia. Las relaciones entre los miembros de la familia son afectuosas y laborales, que al combinarse pueden convertirse en una debilidad o una fortaleza para la familia y la empresa. Según Vélez, Holguín, De La Hoz, Durán y Gutiérrez (2008) estas relaciones familiares sirven para ajustar "las relaciones entre la familia, la propiedad y el negocio". (p.43)

De esta manera, con el tiempo, al irse consolidando la propiedad y los contratos, se van profundizando los lazos entre la familia en sus distintas formas, surgiendo el conflicto como resultado de la marcha del negocio y la actividad familiar. Uno de los conflictos más comunes surge cuando el fundador decide retirarse de la dirección de la empresa, lo cual repercute en el grupo familiar, especialmente, porque este tipo de conflictos incluye las relaciones de consanguinidad. La sociedad del presente, entre padre fundador e hijos debe estar cohesionada junto con el negocio, ya que este debe permanecer en el tiempo, y la sucesión generará presiones de poder que se sumarán al conflicto en dicho proceso.

Amat (2004), por su parte, ha establecido tres etapas en la sucesión: la primera fase es la previa a la incorporación, la cual comprende la formación recibida por los hijos respecto al compromiso con la empresa; la segunda es la de la incorporación, que puede tener dificultades por la falta de funciones claramente establecidas para el sucesor, conflictos entre padre e hijo debido a la falta de delegación del fundador o la desconfianza del padre sobre las competencias del hijo, así como la competencia entre hermanos por la sucesión, entre otros; y la tercera corresponde a la dirección de los sucesores, cuyos inconvenientes pueden presentarse por decisiones inseguras del sucesor, retiro a pasos lentos del fundador, la no aceptación del sucesor por parte de la familia, la falta de un equipo de apoyo.

De acuerdo con Arano, Cano y Olivera (2012), las empresas no son "autosuficientes ni autocontenidas" (p.62), sino que requieren para su existencia de un intercambio con las fuerzas que integran el entorno. El ambiente externo es definido como los elementos extraños a la organización que son importantes para la puesta en marcha de sus operaciones. Las empresas no crean estrategias de la nada, sino que estas deben responder al entorno de la empresa, el cual puede afectar o influir en los resultados de la misma. El entorno puede afectar directa o indirectamente a la empresa, así como puede ser fuente de oportunidades de negocios o impactar con efectos que provoquen daños a estas. La falta de control sobre el entorno hace que las empresas estén enfrentadas a la incertidumbre. Según Zapata, Mirabal y Canet (2015), en un entorno que es cada vez más competitivo, se desarrollan amenazas y oportunidades que implican para la empresa la implementación de estrategias que le permitan un equilibrado ajuste entre las variables internas de diseño organizativo. 
Cabanelas (1997), afirma que el entorno se divide en cinco niveles: el primero, está formado por la empresa en sí misma; el segundo, guarda relación con el sector, el cual abriga al anterior; el tercero, formado por la cadena de actividades empresariales; el cuarto, es el ámbito geográfico, región o área; el quinto, es el más amplio y corresponde a la economía, los factores tecnológicos, políticos, sociales, la naturaleza y hechos fortuitos, así como la actividad empresarial en otras áreas. Para la empresa, es importante, el estudio de los factores del macroambiente como: el gobierno, los intermediarios, los proveedores, el mercado, la economía, la cultura, la política, lo legal y lo natural; así como los factores del microambiente, es decir, recursos, ubicación, instalaciones, tamaño, entre otros.

Es de anotar, que muchos de los elementos del entorno pueden ser de fácil acceso para los miembros de la organización o empresa, puesto que esta información es relevante para la toma de decisiones. Esta información puede estar relacionada con la cotización de productos en el mercado, las preferencias de los clientes por lo productos o motivos y hábitos de compra, las tasas de interés de los bancos, las actividades y estrategias que despliega la competencia (Rendón, 2014).

Respecto al empresario, Schumpeter (2012), expone que el desarrollo económico no se presenta espontáneamente, sino que es impulsado dentro del propio sistema capitalista por intermedio del empresario innovador. Este empresario, no es cualquier persona que pone en marcha una empresa, ni el capitalista dueño del dinero, o del técnico, entre otros. Este empresario es la persona que tiene capacidad e iniciativa para proponer y llevar a cabo nuevas combinaciones de medios de producción. Para este autor, una cosa es ser capitalista y otra ser empresario. Los empresarios son pioneros al incorporar nuevas cosas.

Además, Schumpeter (2012), señala también que producir es la combinación de materiales y fuerzas que estén al alcance de las personas. La producción de estas cosas u otras, por métodos diferentes, representa la combinación de manera distinta de estos materiales y fuerzas. Una nueva combinación respecto a lo que se hacía antes gracias a los pequeños pasos, facilita los cambios y hasta el crecimiento, pero no es un fenómeno nuevo o desenvolvimiento. Esto último, es la puesta en práctica de "nuevas combinaciones". (p.74) producto de: introducción de un bien o una nueva calidad de un bien; un nuevo método de producción sin que tenga que ser un nuevo descubrimiento científico; comienzo de un nuevo mercado; una nueva fuente de aprovisionamiento de materias primas; una nueva organización o industria. Según Schumpeter (2012), el principal cambio no se da en el sistema económico, sino en el individuo, que tiene la necesidad o el deseo de cambiar lo que ya existe, por ello, gesta cosas nuevas. Este deseo convertido en acción mediante la innovación, es la destrucción creativa. El carácter de empresario se pierde cuando se pone en marcha la empresa o cuando se pone a explotar el negocio como los otros. 
Knight (1964), a su vez, afirma que todo lo que el ser humano planea y ejecuta involucra incertidumbre. El mundo es variable y está lleno de incertidumbre, aquí, los agentes sólo conocen de algo que está relacionado con el futuro, mientras que los problemas del mundo y la vida, o al menos, los del comportamiento, surgen del hecho de que se conoce muy poco de las cosas. Existe una distinción entre la incertidumbre mensurable y la no mensurable. La palabra riesgo puede usarse para la incertidumbre mensurable, y la expresión incertidumbre para la no mensurable. La expresión riesgo se usa generalmente en una forma bastante amplia, cuando se trata de cualquier clase de incertidumbre considerada desde el punto de vista de la contingencia desfavorable, y el término incertidumbre, en forma similar, con referencia al resultado favorable. Se habla entonces, de riesgo de una pérdida y de la incertidumbre de una ganancia; pero existe una ambigüedad en estos términos que deben ser evitados. También se puede utilizar la expresión "probabilidad objetiva" (p.234) para definir el riesgo, y "probabilidad subjetiva" (p.233) para la incertidumbre. La diferencia entre las dos categorías, está en que, en el riesgo, la distribución de las situaciones en un grupo de casos se conoce, sea por un cálculo a priori o mediante estadísticas de experiencias que se han tenido; en cambio, en la incertidumbre, no es posible formar un grupo de casos porque el evento que se presenta es único.

De acuerdo con Knight (1964), el problema de la actitud humana frente a la incertidumbre está lleno de dificultades, así como la incertidumbre. La reacción humana ante las situaciones de este tipo puede ser "errática y extremadamente variada de una persona a otra, así que la reacción normal está sujeta a las desviaciones bien conocidas de la conducta que dictaría la sana lógica". (p.235)

Siguiendo con lo expuesto por Smith (1776), los hombres arriesgarán sin mucha dificultad una pequeña cantidad con el fin de ganar una cantidad mayor cuando la "probabilidad adversa (conocida o calculada) para ganar, sea bastante mayor que la proporción de las dos cantidades" (p.235). Por lo general, no gustaran de correr un pequeño riesgo de perder una cantidad muy importante por la certeza de ganar otra pequeña cuantía. También hay que adicionar la creencia por parte de la persona de la propia buena suerte, la cual es muy fuerte "cuando la base de la incertidumbre es la cualidad de su propio juicio". (p.228)

Según Knight (1964) el emprendedor es el agente que deberá convertir una situación de incertidumbre en una situación de riesgo. Así, el emprendedor enfrenta la incertidumbre, especifica los posibles escenarios futuros y valora la probabilidad de ocurrencia. No hace diferencia entre el emprendedor y el dueño de los recursos, aunque diferencia al emprendedor del director.

Para Kirzner (2007), el empresario puro es "un autor de decisiones cuyo papel completo surge de su estar alerta a las oportunidades hasta entonces ocultas". (p.116) o que necesita el empresario, tomador de decisiones, sin medios para tomar la mejor decisión", es saber dónde se encuentran esas 
Aylin Pértuz Martínez, Francia Prieto Baldovino, Wilson Guzmán Cadrazco Parra

oportunidades inexplotadas. El descubrimiento de estas oportunidades necesita de un empresario en alerta. Alerta para descubrir las diferencias de precios entre compras y ventas. El empresario puro "descubre y explota situaciones en las que puede vender a precios altos lo que puede comprar a precios bajos". (p.120)

Asimismo, Varela (2008) plantea una definición ecléctica del empresario así:

El empresario es la persona o conjunto de personas capaces de percibir una oportunidad y ante ella formular, libre e independientemente, una decisión de consecución y asignación de los recursos naturales, financieros y humanos necesarios para poder poner en marcha la empresa, que además de crear valor incremental para a economía, genera trabajo para él, y muchas veces, para otros (p.126).

Este autor señala que en el proceso de liderazgo desarrollado con creatividad e innovación, el empresario invierte recursos como energía, tiempo, dinero y conocimientos, y participa de forma activa en el montaje y operación de la empresa. El empresario no sólo invierte estos recursos, sino que los arriesga junto a su prestigio como persona, en procura de obtener recompensas monetarias o sociales.

\section{Método}

El enfoque de este estudio fue de corte cualitativo, basándose en el concepto de Bonilla y Rodríguez (2005), quienes manifiestan que la investigación cualitativa pretende tomar la realidad de una sociedad, a través de la perspectiva de la gente que es estudiada, en otras palabras, de acuerdo a la percepción que tiene el sujeto del contexto en que está. Según Quecedo y Castaño (2002), estos estudios buscan

"describir sistemáticamente las características de las variables y fenómenos, así como el descubrimiento de relaciones causales", evitando hacer "constructos o relaciones a priori". (p.12)

Asimismo, es un estudio histórico, que se refiere al esfuerzo realizado con la finalidad de establecer los sucesos, eventos, en un ámbito de interés para el investigador (Grajales, 2002). El método de investigación fue analítico-sintético, puesto que, en las investigaciones de tipo histórico, se hace necesario que los sucesos se analicen descomponiéndolos en distintas partes para conocer sus causas, y a partir de este análisis, realizar la síntesis que permita explicar dichos sucesos (Delgado, 2010).

Las fuentes de información fueron principalmente primarias que correspondieron a fuentes vivas y directas (Hurtado, 2012), es decir, la unidad de análisis correspondió los propietarios de la empresa, así como otros empresarios de la ciudad. También se utilizaron fuentes escritas o secundarias.

Para la recolección de la información se utilizó la entrevista no estructurada. Según Díaz, Torruco, Martínez y Varela (2013), la entrevista no estructurada es aquella en la que los sujetos tienen la libertad de sobrepasar las preguntas formuladas o desviarse del plan propuesto. 
En este sentido son más informales y flexibles, planeadas de tal forma, que pueda adaptarse a los entrevistados y a las condiciones. La entrevista se aplicó al empresario Leonel González Anaya, a su esposa y a cinco empresarios pertenecientes al gremio de la ciudad de Sincelejo y fueron realizadas en los años 2013 y 2019.

\section{Resultados}

Almacén LEO: en cincuenta y nueve años, del éxito a la sobrevivencia.

El empresario.

Leonel González Anaya, nació en 1930 en la ciudad de Sincelejo, siendo el mayor de los seis hijos del matrimonio entre Clodomiro González Paternina y Luz Anaya Oviedo. Su padre fue propietario de una tienda de víveres ubicada en el mercado viejo de la ciudad, lugar donde Leonel González desde temprana edad realizó sus primeros ensayos como comerciante tomando las riendas del negocio de su padre en momentos en que éste se ausentaba por periodos prolongados (Gutiérrez, 2013). Efectuó sus estudios hasta cuarto de bachillerato, máximo grado escolar en Sincelejo para aquella época. Realizó un curso de contabilidad en un instituto que dirigía Rafael Castillo, ubicado en el Barrio Chacurí; recibió tutorías de su hermano mayor, Clodomiro González, quien era contador público y pieza fundamental en el emprendimiento empresarial de Leonel González Anaya años más tarde.

Se casó en 1955 con Estevina Ruiz, hermana de los comerciantes Ruiz Tuirán, con quien tuvo cuatro hijos. El empresario se asoció con sus cuñados, propietarios del Almacén Ruiz, donde puso en práctica tanto la experiencia al lado de su padre como su formación académica: contabilista. El Almacén Ruiz, fue la vitrina para que Leonel González se diera a conocer en la comunidad sincelejana, y durante esa estadía fue visionando en el largo plazo la creación de su propio almacén. Para 1960 ya habían nacido sus dos primeros hijos, factor determinante para precipitar la apertura del Almacén Leo Variedades.

De acuerdo con el empresariado: Nunca pensé que me iba a ir mal, al contrario, desde un comienzo le tuve fe a mi negocio. (L. González, comunicación personal, 11 de enero de 2013). Los hijos se profesionalizaron y no trabajaron en el negocio familiar, correspondiendo esta situación a creencias del empresario acerca de la vida empresarial.

El empresario siempre preocupado y conocedor de las necesidades de la comunidad y de su gremio, fue partícipe de la creación de la Defensa Civil seccional Sincelejo en el año de 1955; la Policía Cívica en 1956 y Fenalco capítulo Sucre en 1977. En el trascurso de su vida empresarial recibió varias distinciones por su aporte al comercio sincelejano (Gutiérrez, 2013). 
Inicios: $1960-1975$.

Entre 1956 y mediados de 1960, Leonel Álvarez fue socio y administrador del Almacén Ruiz logrando introducir y posicionar productos como el calzado y ropa, con lo cual logró buenos resultados en el corto plazo. En este almacén obtuvo la experiencia comercial y al mismo tiempo estableció buenas relaciones con los distintos proveedores de mercancías, lo cual fue un punto de inicio para la creación de su propio almacén.

En 1960, decidió, unilateralmente, disolver la sociedad con sus cuñados-los hermanos Ruiz-. Se percató que el mercado de ropa masculina de fábrica en Sincelejo se caracterizaba por ser un sector escasamente explotado. Consecuencia de esto, era la existencia de una vasta oferta de sastrerías y almacenes dedicados a la venta de telas para satisfacer las necesidades de vestir de los habitantes; en la ciudad era común el uso de la camisa blanca y el pantalón de color caqui (color marrón pálido de los pantalones de uso militar en esa época).

La liquidación de $\$ 18.000$, y los créditos otorgados por parte de proveedores de diversas marcas de productos terminados como Calzado La Corona, Manufactura Tropical, Croydon, Slaconia, Everfit, Van Heusen, Cicodec, Lord, Valer, Trianón y Triunfo Unión, fueron el capital o recurso financiero para iniciar la empresa. El 25 de noviembre de 1960 se efectuó la apertura del establecimiento comercial Almacén Leo Variedades.

El Almacén Leo Variedades, se ubicó al principio en un local en la carrera 19 No 21-48 de la calle Real. Dicho local era de Luis Herazo Salom, quien lo arrendó al empresario por $\$ 85$ mensuales. Este sitio fue escogido por ser un importante corredor comercial en Sincelejo, donde convergían almacenes de variedades, confecciones y ferreterías, entre los cuales se encontraban: Ferretería Olivares (José María Olivares), La Cabaña (Roberto Támara), Papelería Medellín (Libardo Gomes Vallejo), Agencia de pinturas, Farmacia Castilla, Farmacia Rex, Farmacia Támara, Agencia de Vehículos Willies, Almacén el Encanto, el Caballero Elegante (Eusebio Benítez), Almacén París (cosméticos), Ferretería Hernández (Rafael Hernández), Almacén Radión (Roberto Angulo), Almacén Iberia, Hotel Palace (Pablo Samur). Estos negocios tenían una característica en común: todos los propietarios eran sincelejanos.

La gestión administrativa, como el manejo de la caja y proveedores, fue potestad de Leonel González; en la parte de ventas tenía dos vendedores encargados de la exhibición y atender a los clientes, aunque en la mayoría de las ocasiones era una labor desempeñada por el mismo propietario, que siempre ha considerado que el contacto directo con el cliente es importante para fidelizarlos. (L. González, comunicación personal, 5 de febrero de 2013) 
Por otra parte, el manejo contable estuvo a cargo de Clodomiro González hasta el año de 1968. En esta tarea siguió Elsa Gómez hasta 1985, y luego, el contador Francisco Contreras, quien ha llevado los registros contables hasta tiempos actuales. Las vendedoras fueron seleccionadas por referencias personales, a través de un contrato verbal y un pago quincenal.

En su estrategia de ventas el almacén ofreció créditos a los clientes. Dichos clientes eran bastantes conocidos y contaban con un volumen de compras considerable que, en opinión del empresario, los hacía merecedores de ese beneficio. Los precios que se manejaban en la época eran precios de fábrica, directriz que aún se mantiene. Con esta política de precios, un buen día de ventas oscilaba entre $\$ 12$ y $\$ 20$ que permitían consignar parte del pasivo a los proveedores cuyo plazo máximo era de 60 días.

La relación con los proveedores estaba cimentada en la confianza de años anteriores. Era costumbre la visita de los vendedores-representantes de los proveedores-al almacén a ofrecer sus productos y satisfacer las necesidades de inventario del almacén.

Los activos del almacén comprendían los inventarios y muebles necesarios; cinco años más tarde de la apertura, se adquirió una caja registradora de marca alemana-Hugin-que registraba solo cantidades de dos dígitos, para darle mayor organización al flujo diario de efectivo. Es de anotar que para la época se emitían billetes con denominaciones de $\$ 1, \$ 5, \$ 10$ y $\$ 20$.

En cuanto a la competencia del almacén, estaba conformaban por dos grupos: las sastrerías importantes de la época como fueron los Hermanos Paternina (iniciadores de la venta de zapatos marca La Corona en Sincelejo), Sastrería Boston y el Caballero Elegante, consideradas por el empresario como una competencia indirecta, mientras las personas cogían el gusto por la ropa de fábrica. El otro grupo era la competencia directa quien estaba conformada por los almacenes Ruiz y Carmencita, que tenían distintas líneas de productos, con mercancía manufacturada parecida a la ofertada por el Almacén Leo Variedades. Estos dos últimos establecimientos representaban una competencia caracterizada por ser entre amigos (L. González, comunicación personal, 11 de abril de 2013), basada en la confianza y lealtad, pues había muestras de cooperación entre unos y otros. A propósito de esta situación, el señor William Quessep, empresario de la época expresó: Existía una buena empatía entre el comercio de Sincelejo, la demostración de eso era que al comerciante que tenían flaquezas económicas se le ayudaba. (W. Quessep, comunicación personal, 8 de mayo de 2013)

Uno de los problemas que tuvo el almacén y la comunidad sincelejana, fue lo relacionado con los servicios públicos, especialmente el de acueducto. El almacén no contaba con este servicio, por lo cual tenía que buscar mecanismos diferentes para la obtención del agua, comprándola o llevándola de su casa, pero en términos generales, el Almacén Leo Variedades no presentaba dificultades o imprevistos de relevancia en su accionar comercial. En relación con la parte financiera, ésta se caracterizaba por 
Aylin Pértuz Martínez, Francia Prieto Baldovino, Wilson Guzmán Cadrazco Parra

mantener una buena liquidez para responder a sus obligaciones con los distintos acreedores en el corto plazo; esto se evidenciaba al no tener la necesidad de hacer préstamos bancarios para estos fines.

El almacén abría sus puertas todos los días, en una jornada continua desde las 8:00 am hasta las 6:00 pm. Los domingos mejoraban las ventas, puesto que era el día de llegada de las familias hacendadas de pueblos y corregimientos aledaños a la ciudad para hacer sus compras y visitas sociales. Muchos de los clientes provenían de pueblos circunvecinos. Las temporadas del año más atractivas en términos de ventas para el almacén, estaban sujetas al ciclo ganadero de la sabana.

En ese sentido, el señor Leonel González manifestó:

Los meses de mayores ventas del almacén eran noviembre; diciembre; enero, por las fiestas del Dulce Nombre de Jesús, y la Semana Santa; además, las temporadas de vacaciones y fin de año tenían la particularidad de la llegada de personas residentes en Venezuela que visitaban el almacén para hacer sus compras. (L. González, comunicación personal, 11 de abril de 2013)

En los primeros años el almacén poseía unos 90 clientes fijos, pertenecientes a familias acomodadas de la región, domiciliados en Sincelejo, Chochó, La Arena, Sincé, Corozal, Colosó, San Marcos, Sampués, San Onofre, Ovejas, Montería, Sahagún, Lorica y Magangué. La mayoría de estos clientes se dedicaban a la ganadería. Más tarde se fueron sumando clientes de Pueblo Nuevo, Ciénaga de Oro, Planeta Rica, Cereté, San Jacinto y Carmen de Bolívar. Esta captación de clientes era producto en gran medida de la costumbre de las personas por llegar de los distintos pueblos a Sincelejo que era epicentro comercial de la Sabana de Bolívar, tal como manifestaron algunos empresarios de la época, entre ellos Wiliam Quessep (W. Quessep, comunicación personal, 30 de abril de 2013), y los señores Julio Corena (J. Corena, comunicación personal, 30 de abril de 2013) y Ramón Fernández (R. Fernández, comunicación personal, 30 de abril de 2013); a pesar que Montería era capital del Departamento de Córdoba desde 1952.

En 1964, Leonel González, decidió ampliar las líneas de productos con el renglón de damas y niños, en aras de satisfacer las necesidades del buen vestir de estos segmentos, y así tener un mayor alcance y participación en el mercado de ropa y calzado en la región. El aumento del volumen de inventarios, de las ventas y del flujo de clientes, hizo que la atención se tornara incomoda. Las dimensiones del local ya no eran óptimas para el nivel de operaciones comerciales del momento. Diagonal a la ubicación de Almacén Leo Variedades se encontraba un local de Humberto Urzola, que lo tenía arrendado a Manolo Matos, que a su vez había establecido una agencia de Máquinas y Repuestos Singer. De esta forma, Leonel González le propuso a Matos pagar una prima, es decir una especie de valor agregado del mercado, de $\$ 25$ para que le cediera el local. Según el empresario Leonel González fue la primera prima pagada en Sincelejo: En esa época no se hablaba del concepto de prima, se logró arrendar el local ofreciendo un dinero al arrendatario-Manolo Matos-para que mí oferta de arrendamiento primara por encima de los demás 
Aylin Pértuz Martínez, Francia Prieto Baldovino, Wilson Guzmán Cadrazco Parra

interesados por el mismo inmueble. (L. González, comunicación personal, 4 de junio de 2013). De ahí en adelante se arrendaban y cedían locales a través de estos pactos.

En 1965 trasladaron el Almacén Leo Variedades al nuevo local ubicado en la carrera 19 No. 21-49, acto seguido, Leonel González, logró ampliar y fortalecer el segmento de caballeros, damas y niños e introdujo los vestidos enteros, smoking y telas, atendiendo las sugerencias de los clientes. De esta forma se alcanzaron a cuantificar un inventario de unos $\$ 80.000$ mil pesos. La fachada de los almacenes de la Calle Real, estaban de acuerdo con la arquitectura republicana y art deco; los avisos publicitarios eran simples, elaborados de pintura y ubicados de forma horizontal en el frente de cada local. William Quessep expresó: En la mayoría de los negocios de la época, la exhibición de las mercancías es a base de mostradores y vitrinas sencillas, los adornos especiales en la decoración e incorporación de maniquíes se empieza con los almacenes Cristal, Carmencita y Beatriz. (L. González, comunicación personal, 4 de junio de 2013). El almacén siguió dicha tendencia, realizándose algunas mejoras en el local.

El empresario fue pionero en la comercialización de la marca Trianon, marca colombiana especializada en productos de marroquinería de calidad fundada en 1935 en Armenia, años después introdujo en el mercado local la marca nacional Kosta Azul originaria de Pereira. En 1966 el empresario compró el Almacén Roble dedicado a la venta de blue jean y ropa informal de marca Roble, manufacturada en Bucaramanga. En esta oferta de mercancía se manejaba precios populares y una calidad un poco menor a la ofertada en el Almacén Leo Variedades, comentó Leonel González (L. González, comunicación personal, 4 de junio de 2013). La intención del empresario con esa adquisición era captar otra porción del mercado, es decir, satisfacer las necesidades de aquellos clientes cuyos ingresos no les permitían consumir productos de la calidad de Almacén Leo Variedades.

Después de nueve años el Almacén Roble, bajo la administración de Adalberto Arrázola, fue liquidado debido a que los propietarios de Manufacturas El Roble (marca registrada) tomaron la decisión de abandonar el mercado nacional, para dedicarse exclusivamente a exportar sus productos a Venezuela, México y Centro América. Esta fue la vez que Leonel González intentó incursionar en otros negocios independientes al almacén; contó con la oportunidad de abrir un almacén similar en Montería, pero no encontró administradores de confianza para una gestión con buenos resultados. Además, expresó que en la época no se contaba con herramientas informáticas y computacionales que me permitieran una supervisión en tiempo real de las ventas y demás operaciones del otro almacén. (L. González, comunicación personal, 4 de junio de 2013)

A principios de los años setenta se consolidaron competidores locales ubicados en el mismo segmento, como el Almacén Carmencita, pionero en la comercialización de la marca Pat Primo, el Almacén Beatriz y el Almacén Ruiz. El almacén amplió la oferta de productos, pero el mercado objetivo no respondió a ese incremento, lo cual provocó una leve caída en las ventas y la reducción de las utilidades. En 1973, su 
Aylin Pértuz Martínez, Francia Prieto Baldovino, Wilson Guzmán Cadrazco Parra

propietario tomó la decisión de no atender el segmento femenino debido a su menor rotación, ya que, de acuerdo con el empresario, un aspecto determinante de esa decisión era que para esta época la costumbre era que el hombre trabajaba y en muchas ocasiones disponía del gasto del dinero en el hogar. Muy pocas mujeres generaban ingresos. (L. González, comunicación personal, 4 de junio de 2013). Por tanto, eliminaron la expresión Variedades y colocaron el eslogan Tradición y calidad. Con el consentimiento del dueño del local, se redujeron las dimensiones, siendo las mismas actualmente. El almacén desde esa fecha ha contado con tres personas: el propietario, su esposa y una vendedora.

En los inicios de los años setenta, empezaron a invertir esporádicamente en publicidad. Las primeras pautas publicitarias fueron en la emisora de frecuencia am Radio Sincelejo, dirigida en este momento por Germán Gómez Peláez, a un costo de $\$ 12$ mensuales. Entre los años sesenta y setenta estas estrategias de mercadeo no tenían mucho impacto en el gremio comercial de la ciudad, porque entre otras cosas, como manifiesta el locutor radial de la época, Nadín Miserque: Los comerciantes no estaban acostumbrados a la publicidad radial [...], la pauta era producto más de amistad que de necesidad del sector comercial (N. Miserque, comunicación personal, 7 de febrero de 2014).

Consolidación, quietud, crisis y recuperación: 1976 - 1986.

El Almacén Leo siguió consolidándose a pesar de la competencia de los almacenes Carmencita y Beatriz, que ya tenían un crecimiento notorio. No obstante, la relación de los empresarios era muy cordial, pues una rivalidad agresiva no tenía cabida. Muestra de ese ambiente de cofradía era la cooperación y el intercambio de mercancía, que según el empresario: Al momento de que algún almacén tiene excedentes de un producto determinado del que otro carece, simplemente se hace el cambio (trueque) de esa referencia por una distinta. Hoy en día estas muestras no se presentan, sin embargo, el entendimiento comercial y de amistad continua. (L. González, comunicación personal, 4 de junio de 2013).

El tipo de cliente del almacén se diversificó sustancialmente, pero los ganaderos continuaban con la mayor participación. Esta notable variedad de clientes obedecía a que, a mediados de la década del setenta, Sincelejo ya era capital del departamento de Sucre. La creación del departamento de Sucre dio un empuje económico importante a la ciudad de Sincelejo, evidenciado en la cobertura y mejoramiento de los servicios públicos (educación, salud, domiciliarios, comunicaciones, seguridad); la creación de la Universidad de Sucre en el año de 1978; mejoramiento urbanístico; entre otras acciones. Del interior del país llegaron empresas como Almacenes Ley, y J. Glottman. De Barranquilla, en la década de los ochenta arribó el Supermercado Olímpica.

De esta forma, el Almacén Ley, ubicado frente a la Catedral, coadyuvó a la modernización que necesitaba el comercio local. Los comerciantes empezaron a preocuparse por tener sus negocios organizados por secciones para permitir la entrada a los clientes, de tal forma que pudieran escoger sus 
Aylin Pértuz Martínez, Francia Prieto Baldovino, Wilson Guzmán Cadrazco Parra

productos; instalar cajas registradoras; decorar los almacenes acordes al segmento del mercado objetivo; uniformar a los empleados.

Un contexto relativamente estable en su mercado objetivo y cierta pasividad comercial en la ciudad, como caracteriza, de cierta forma, al empresariado sincelejano de ese período, el empresario Jorge Montes le permitió al almacén buenos resultados operacionales. Para la época visitaron distintos proveedores en la ciudad de Barranquilla, tales como, Manufacturas Tropical, Calzado Prieto, Calzado Trevi, Fábrica de Pantalones Scotland; luego seguiría Medellín con Manufacturas de Cuero Macel, Fábrica de calzado Triunfo Unión, Fábrica de Calzado Ago.

Al finalizar la década del setenta masificaron la costumbre del crédito en el sector comercial. El Almacén Leo flexibilizó sus políticas de créditos, evidenciándose un aumento considerable en las ventas con esta modalidad, dando como resultado la ampliación en el periodo de cobro. Pero se presentó un incumplimiento en los pagos por parte de los clientes, a tal punto que el 30\% de su cartera estaba vencida y era de difícil cobro.

En los años 1978 y 1979 sucedieron episodios esporádicos de insolvencia financiera para atender las obligaciones con los distintos proveedores, por lo que tuvieron que acudir al crédito bancario. Fue necesario restringir el crédito a los clientes y solo se los otorgaban a personas conocidas. Algo que compensaba las pérdidas en los créditos otorgados, era el costo de los arriendos en ese momento, eran casi irrisorios, porque tal vez, no se manejaba el concepto de estrato comercial en los locales del sector", expresó Leonel González (L. González, comunicación personal, 4 de marzo de 2015). Este periodo de dificultad en términos financieros se acentuaría en 1980, coincidiendo con la caída de las corralejas en Sincelejo. En el sector comercial muchos almacenes trabajaron a pérdida, por el dramático descenso en las ventas en los meses posteriores. El primer mes de cada año fue casi nulo en el ámbito comercial de la ciudad por largo tiempo. La recuperación del almacén se dio en 1984.

Después de superar la anterior crisis, el almacén se estabilizó y reportó utilidades netas importantes. Parte de ellas fueron invertidas en los estudios de secundaria y universitarios de sus hijos.

Como anécdota, en 1981, el empresario cambió la caja registradora que venía utilizando, puesto que no registraba cantidades superiores a cien pesos. Según Rosero (2009), el Banco de la Republica había cambiado las denominaciones hacia 1969 y la década del setenta $(\$ 100, \$ 200, \$ 500)$. Esta situación es una evidencia de los escasos recursos tecnológicos utilizados por la empresa.

Entre 1985 y 1986, el empresario aceptó servir de proveedor a personas que revendían esos productos a crédito en los pueblos de San Pedro, Magangué, Mompox, Sahagún, San Marcos, Tolú, Majagual, Sucre, entre otras poblaciones. Las ventas con esta modalidad aumentaron progresivamente sin afectar el 
Aylin Pértuz Martínez, Francia Prieto Baldovino, Wilson Guzmán Cadrazco Parra

accionar del almacén. Las utilidades le permitieron financiar parte de los estudios de uno de sus hijos en el exterior.

Ligeros cambios y nueva crisis: $1987-2000$.

En año 1987, colegas y amistades de Leonel González le ofrecieron ser socios capitalistas, con el propósito de abrir almacenes con la misma razón y objeto social en Cartagena, Montería y Magangué. La respuesta del empresario siempre fue negativa al considerar que su negocio era sólido y de los pocos con buena reputación. (L. González, comunicación personal, 4 de marzo de 2015).

Dado que la competencia publicitaba cada vez más en medios impresos y sonoros el Almacén Leo efectuó pautas radiales en: Radio Sincelejo, Ecos de la Sierra Flor y Transmisora de Sucre (quien años después pasaría a llamarse RCN Radio), además de cuñas publicitarias en eventos deportivos como el softbol, encuentro de bandas y fiestas patronales en los distintos pueblos aledaños.

Al final de la década de los ochenta al almacén le realizaron algunos cambios en estanterías y maniquíes, sin embargo, en términos generales el almacén continuó con su decoración sencilla y señorial que lo ha caracterizado por más de cincuenta años.

Los beneficios económicos obtenidos del negocio fueron invertidos en la adquisición de activos de finca raíz y semovientes en otro municipio, pero esta inversión no fue de carácter empresarial de manera formal, sino que fue tomada como una actividad a muy pequeña escala e informal.

Para 1987, varias empresas manufacturas proveedoras del almacén cerraron sus puertas, mientras que otras se enfocaron en comercializar mercancías en sus ciudades de origen, abandonando las ventas al por mayor en otras ciudades. Fue el caso de Manufactura Tropical (fabricación de pantalones), que se liquidó, y Calzado Trevi que se limitó a fabricar y vender exclusivamente en Barranquilla.

Por su parte, el Almacén Gino Pascalli y Pierre Lui llegaron a la ciudad en 1994 y 1995, junto con otros almacenes o tiendas cuyos propietarios provenían del Eje Cafetero y Antioquia.

En los últimos años de la década del ochenta y principios de los noventa el almacén amplio el portafolio de marcas y proveedores, entre ellas: Giotto di Bone (1987), Punto Blanco (1987), Pat Primo (1986), Industrias Naga (1991), Kosta Azul (1985), Mar Janna (1990), Gino Di Santis (1990), Calzado Braun (1994), Gabucci, Pierre Mani (1993), Bassoti (1992). Esta estrategia le reportó buenas utilidades netas hasta la primera mitad de la década del noventa.

Para esta época, Sucre ya no era un núcleo ganadero. Según Aguilera (2005), el departamento de Sucre para 1988 tenía cerca de 750.000 cabezas de ganado y en 1990, seguía con un inventario un poco superior a este número. En 1990 el sector que más aportó al PIB departamental fue el terciario (comercio, administración pública, salud, servicios públicos, bancos) con el 49,2\%; en cambio, el sector primario- 
Aylin Pértuz Martínez, Francia Prieto Baldovino, Wilson Guzmán Cadrazco Parra

ganadería y agricultura -contribuyó con un 43,7\%. El bajo crecimiento de la ganadería sucreña tuvo como causa la inseguridad rural y el consumo de productos sustitutos como el pollo.

Por otro lado, la presencia de los grupos armados al margen de la ley, obligó a muchos ganaderos de la región a liquidar sus hatos y establecer su residencia en otras ciudades. Unos invirtieron su dinero en sectores de menor exposición, entre esos el comercio local y regional; acerca de esta situación el empresario manifestó: En el periodo, muchos clientes del almacén dedicados a la ganadería son extorsionados y algunos secuestrados, la única solución que vieron fue abandonar el país. Este tipo de clientes disminuye drásticamente. (L. González, comunicación personal, 4 de marzo de 2015). El segmento que compensó esta disminución fue el de los profesionales, teniendo en cuenta que en la década de los ochenta y mediados de los noventa existía un número significativo de profesionales egresados de universidades de Barranquilla, Cartagena, Santa Marta, Medellín y Bogotá. En Sincelejo ya hacían presencia dos importantes universidades y a finales de los noventa incursionaron varias Instituciones de Educación Superior en la ciudad.

Años más tardes, en la segunda mitad de los noventa la situación socio-económica del país se vio afectada por la conjunción de tres factores: el conflicto armado interno llegó a su punto más alto, reflejando altos índices de violencia generalizada en todo el país; la crisis institucional por el endeudamiento creciente de los entes departamentales y locales, donde se gastaba más de lo que lo que sus ingresos les permitían; y, la crisis financiera que estalló en 1999, causada en gran medida por la apertura a los mercados financieros internacionales, expandiendo excesivamente el sistema financiero tanto en número de entidades como en colocación de crédito (Rodríguez, 2004). En lo político, la corrupción política tuvo como eje el proceso 8.000, en el que el electo presidente Ernesto Samper Pizano (1994-1998) fue denunciado por la financiación de su campaña por parte del narcotráfico, lo cual generó una crisis política, económica, de relaciones internacionales y de orden público en el país, siendo un gran obstáculo para el logro de las metas del plan de desarrollo (Puche, 2011).

En este sentido, el departamento de Sucre presentó entre 1995 y 2002 en su actividad económica un decrecimiento promedio anual de $0.2 \%$, que produjo un gran desempleo local. Asimismo, el desplazamiento forzado como resultado del conflicto armado generó un gran crecimiento de la población en Sincelejo. De acuerdo con los datos de la Red de Solidaridad desde 1996 hasta abril de 2005, el departamento de Sucre absorbió 106.451 personas desplazadas por la violencia de otras regiones, de las que 67.884 llegaron a vivir a Sincelejo, esto produjo un "desequilibrio entre las necesidades existentes y la satisfacción de ellas" (Aguilera, 2005, p. 21). El fenómeno, llamado hoy "mototaxismo", fue una respuesta para reducir el desempleo en este momento (Sánchez, 2011).

En el Almacén Leo, el punto crítico de esta crisis, fue desde 1998 hasta el año 2000, período donde se bajaron las ventas en un $60 \%$. El empresario tuvo que apalancar su capital de trabajo con entidades 
Aylin Pértuz Martínez, Francia Prieto Baldovino, Wilson Guzmán Cadrazco Parra

financieras con créditos de siete y seis millones de pesos. Así lo expresó el empresario: El monto de esos préstamos eran destinados para el pago de proveedores y servicios. De esta forma se mantenía el almacén hasta salir de la crisis. (L. González, comunicación personal, 4 de marzo de 2015)

Las expectativas de Leonel González en términos de ventas, con la reanudación de la fiesta taurina en el año 1997 no fueron satisfechas. Un aspecto negativo fue la reubicación de las corralejas en la zona perimetral-salida a Sampués-, dado que los visitantes de los pueblos aledaños ya no ingresaban al centro de la ciudad. Además, las costumbres sincelejanas ya habían cambiado, ya no era importante la elegancia para asistir a las corralejas y los bailes de clubes como en los años cincuenta, sesenta y setenta.

Igualmente, la crisis del almacén, coincidió con la notificación que realizó el Ministerio de Hacienda en septiembre de 1998 al Municipio de Sincelejo, exigiendo el pago de los 2.000 millones de pesos por la indemnización de los fallecidos en la caída de las corralejas en 1980 (Redacción El Tiempo, 24 de septiembre de 1998), lo cual afectó indirectamente el pago de los salarios y prestaciones sociales de los empleados del sector público, especialmente a los funcionarios quienes en su mayoría eran clientes del Almacén Leo. Algo importante para rescatar en esos años difíciles, fue la solidaridad de algunos de los proveedores de Almacén Leo, al ampliarle los plazos hasta 120 días sin incurrir en tasas de mora. La reducción en las ventas obligó al empresario a establecer en 1999 una estrategia coyuntural que consistía en un descuento del $10 \%$ sobre las ventas, esto con la intención de dinamizar las ventas la cual se quedó hasta la actualidad.

\section{Mayor competencia, crisis e incertidumbre: desde años 2000 hasta la actualidad.}

La etapa de reactivación de la economía en Colombia, iniciada en el 2000, fue benéfica para la mayoría de los departamentos de la costa Caribe, pero en Sucre se evidenció dos años más tarde. Este atraso fue producto de la estructura productiva del departamento predominantemente agropecuaria y dependiente de un mercado interno. (Aguilera, 2005). No obstante, la estabilización de las ventas en el Almacén Leo se dio en el año 2002, que gran parte de esta recuperación se debió a los precios relativamente estables: al descuento del $10 \%$ a los clientes, al entendimiento con los proveedores consientes de la crisis atravesada por el país, y a los clientes fieles de los pueblos aledaños.

Para los primeros años del nuevo milenio a la ciudad de Sincelejo arribó una avalancha de almacenes ofreciendo particularmente indumentaria informal y casual. En el 2003, intentaron participar en el mercado de ropa informal y casual, para atraer a los hijos de sus clientes, sin embargo, la estrategia no resultó, en gran parte porque la gente tenía la percepción de un Almacén Leo tradicional, con más de cincuenta años ofreciendo exclusivamente ropa clásica y formal. No se invirtió en una publicidad específica y distintiva de la nueva mercancía a ofrecer, tampoco se marcó en el local una separación entre lo clásico - formal y lo informal-casual, y, además, la atmósfera del local siguió de igual manera. 
Para la primera década del 2000, el Almacén Leo mantuvo un bajo perfil, no pudieron hacerle arreglos al local al no poder comprarlo a su dueño Humberto Urzola. Aunque bien ubicado, tenía poco espacio para una mayor exhibición de mercancías. En contraste, los almacenes Carmencita y Beatriz se mantuvieron vigentes y posicionados en el comercio local, experimentando cambios en términos de su oferta, organización e infraestructura física.

En octubre de 2009, el Departamento Nacional de Planeación (DNP) incluyó a Sincelejo en la estrategia: Ciudades Amables. El objetivo del proyecto era reorganizar y modernizar el transporte público colectivo en 12 ciudades intermedias de menos de 600 mil habitantes: Santa Marta, Valledupar, Sincelejo, Montería, Manizales, Armenia, Buenaventura, Ibagué, Villavicencio, Neiva, Popayán y Pasto; esto iba acompañado de una transformación de la malla vial; mejoramiento de vías; construcción de andenes y bordillos; y semiterminales (Redacción El Tiempo, 2009). Estas obras solo se ejecutaron hasta el 2015. En el plan de mejoramiento de vías céntricas, incluyeron la carrera 19, la cual empezó a intervenirse en agosto de 2011, con un frente de trabajo propio que laborará a doble turno, para culminar la obra en máximo un mes, precisó Dairo Romero Rojas gerente del FOMVAS en su momento (Pérez, 2011).

Desafortunadamente, las obras se retrasaron y los comerciantes del sector, observaron la disminución de sus ingresos por ventas debido a lo intransitable de la vía. El cerramiento de la Calle Real demoró alrededor de cinco meses, afectando las ventas de final de año de Almacén Leo. Los clientes prefirieron las tiendas del Centro Comercial San Francisco o realizaron sus compras en Montería, Cartagena y Barranquilla, según manifestó Leonel González y su esposa Estevina Ruiz (L. González y E. Ruiz, comunicación personal, 13 de agosto de 2018). Además de eso, según el empresario, los comerciantes de la calle no recibimos ningún tipo de subsidios para el pago de los servicios y arriendo, tampoco redujeron los impuestos (L. González, comunicación personal, 13 de agosto de 2018). La falta de parqueaderos en el centro de la ciudad, y la prohibición de parquear en sus calles, también fue un factor de preferencia por los centros comerciales actuales. Aunque en estos momentos ya cambió la disposición, es decir, las Zonas de Estacionamiento Regulado, es pago, a diferencia de los centros comerciales (Viva y Guacarí), cuyos parqueaderos son gratuitos.

Una característica del Almacén Leo es la falta de acercamiento de los hijos del empresario Leonel Álvarez en las labores del negocio. Para ir desarrollando en ellos las competencias administrativas y/o emprendedoras, Leonel Álvarez no involucró a ninguno de sus hijos en la empresa, prefirió guiarlos y cerciorarse de que emprendieran una formación profesional. Al respecto, el empresario afirmó: El ser comerciante es un oficio absorbente e incierto, que requiere de mucho sacrificio durante la mayor parte de la vida, por eso preferí que mis hijos optaran por algo un poco más seguro. (L. González, comunicación personal, 2 de septiembre de 2015) 
El empresario ha dedicado 58 años de su vida al Almacén Leo de manera continua, junto a su esposa que se le sumó a partir de la década del ochenta. Hacia el año 2013, el empresario contempló la opción de retirarse del comercio para darse un merecido descanso. A raíz de esto y motivada por su edad, cambiaron la razón social, con la incorporación de los hijos en la sociedad, conformándose el Grupo Empresarial Leo, pero la carga impositiva fue muy alta, y dado el fallecimiento del hijo mayor, decidieron regresar a la razón social Almacén Leo, siendo actualmente los socios: la esposa, Estevina Ruiz, los tres hijos de la pareja, y los hijos del socio fallecido. Actualmente Leonel González no es socio de la empresa y como gerente quedó designada Estevina Ruiz.

En el 2019, la empresa afronta una situación crítica, debido a las dos intervenciones en infraestructura vial de los últimos años en el centro de Sincelejo que obstaculizaron el acceso de los clientes al almacén, y las condiciones económicas del país, teniendo en cuenta que sus productos no son de precios económicos, según comentó el empresario. (L. González, comunicación personal 5 de febrero de 2019).

A raíz de esto, el estado de resultados mostró pérdidas en los últimos cinco años, debido a las ventas escasas, por lo expuesto anteriormente, así como por los cambios en los motivos y hábitos de compra de los clientes. La atmósfera del almacén continúa siendo muy conservadora, manteniendo el mismo estilo de décadas pasadas. El futuro ya está en manos de sus hijos, aun cuando, Leonel González, asiste todos los días a su empresa.

\section{Discusiones}

La historia de la empresa Almacén Leo muestra en sus inicios lo que Schumpeter (1997) expone con respecto al empresario innovador, puesto que el propietario del Almacén Leo dirige su negocio al segmento de caballeros en los estratos medio y alto con productos de calidad en los años sesenta, a diferencia de los otros tres almacenes (Almacén Carmencita, Almacén Ruiz y Almacén Beatriz), los cuales atienden los segmentos masculino y femenino en los mismos estratos, es decir, Almacén Leo concentra su atención en un mercado o nicho objetivo más específico, en este caso, Gonzales es un empresario y pionero, no solamente capitalista. Así mismo, es consecuente con lo expresado por Kirzner (2007), ya que el empresario detecta y aprovecha una oportunidad en el mercado. El empresario ha invertido en la empresa los distintos recursos señalados por Varela (2008) y, así mismo, se observa su participación activa en la creación y puesta en marcha de la empresa en todo el transcurso de su historia. El empresario arriesgó su prestigio personal para brindarle a su familia mejores horizontes, aspecto mencionado por Varela (2008), como un elemento del concepto de empresario.

El desarrollo del almacén, tal como tiende a ser en la naturaleza de los negocios, ha estado inmerso en el riesgo y la incertidumbre. La incertidumbre se visibilizó con la apertura de la tienda para el segmento ya señalado, siendo una situación comercial nueva en la ciudad. Posteriormente, el almacén afrontó 
Aylin Pértuz Martínez, Francia Prieto Baldovino, Wilson Guzmán Cadrazco Parra

momentos de incertidumbre por factores sociales o económicos, y periodos en riesgo, relacionados con las decisiones de adquisición de inventarios para las temporadas de cada año.

Así como lo establece Knight (1947), la reacción humana ante la incertidumbre es diferente entre las personas. En el caso del empresario Leonel González, se observa una aversión al riesgo posterior a los inicios de la empresa, su decisión al momento de abrir el almacén se da en un marco de incertidumbre, pero su acción está guiada por sus deseos de generar recursos económicos propios para la familia para tener un mejor futuro. En cambio, sus decisiones posteriores muestran un estilo conservador en la toma de decisiones. La única acción que ejecuta para ampliar el horizonte empresarial, culmina años después por factores externos, pero no se encamina a una nueva oportunidad, tanto así que rechaza otras ofertas comerciales de expansión, dado que tampoco desea asumir la incertidumbre ante una asociación.

Sin embargo, esta empresa, que ha cruzado la línea de los cincuenta años de existencia, de carácter familiar, según lo establecido por Aguilar y Ocampo (2018), tiene como característica especial, que los hijos no fueron educados para continuar con el negocio. El empresario decidió, que era mejor la orientación de estos hacia profesiones liberales, lo cual es muestra de su aversión al riesgo y la incertidumbre. Obsérvese que el empresario decidió invertir en la educación de sus hijos, y no realizó reinversiones importantes de utilidades en el negocio para su consolidación o expansión. En este sentido, la sucesión no ha seguido el proceso enunciado por Amat (2004), en virtud a la edad del empresario y la no presencia de los hijos en la empresa, de tal manera que es importante el desarrollo de investigaciones acerca de la continuidad de la empresa por parte de la segunda generación, cuando los herederos no se incorporan al negocio en épocas tempranas y su incidencia en la supervivencia de la empresa en el contexto de la costa Caribe.

La empresa cuenta en su recorrido con recursos internos limitados, como se evidencia en sus finanzas y tecnología, además es impactada positiva y negativamente por factores de contexto, tanto del macroambiente como del microambiente. El empresario reconoce los factores externos que llevan al almacén de una buena situación comercial y financiera a una situación de crisis, siendo en este último caso las desaceleraciones de la economía, las disposiciones gubernamentales, eventos trágicos en la sociedad sincelejana, la alta competencia proveniente de otras regiones, la atracción de los clientes por los centros comerciales. Asimismo, los factores positivos: la demanda en las primeras décadas, existencia de marcas reconocidas, el interés por la calidad y la moda. Pero también hay factores internos que han incidido de forma negativa: la falta de una gerencia estratégica, la fragilidad financiera, estilo de administración conservador, aversión al riesgo, entre otros.

\section{Conclusiones}

Hemos visto a lo largo de este artículo que la empresa tuvo períodos de éxito, representados en las primeras décadas de su existencia, y momentos de crisis de forma casi permanente, en lo transcurrido del 
Aylin Pértuz Martínez, Francia Prieto Baldovino, Wilson Guzmán Cadrazco Parra

siglo XXI. Por un lado, sus momentos de éxito se han evidenciado en el crecimiento de las ventas, el cambio y ampliación del local, siendo favorecidos por un segmento de mercado, en gran parte unido al sector agropecuario y por otro lado, en épocas de crisis se ha tenido una gran disminución en las ventas, pérdida de la clientela, iliquidez.

Se observa que la empresa ha formulado diversas estrategias para mantenerse en el mercado, la cuales se han convertido posteriormente en estrategias de status quo. La acción publicitaria ha sido muy escasa y sólo manejó una estrategia de expansión de mercados hacia el segmento de ropa casual, por varios años. Asimismo la estrategia de diversificación de líneas no fue exitosa y La línea de ropa clásica masculina ha sido una impronta que ha quedado en la clientela de la región sabanera.

La gerencia ha estado en manos de Leonel Álvarez Anaya, y su esposa Estevina Ruiz ha fungido como asistente y vendedora. Las decisiones administrativas, operativas, de ventas y financieras han sido potestad del empresario. El empresario se ha caracterizado por un estilo bastante conservador en la toma de decisiones, en su actitud frente al cambio y la actitud asumida frente al fracaso. Ha tenido una capacidad de negociación positiva lo cual se observa en el tratamiento recibido por los proveedores y acreedores en los períodos de crisis. La habilidad innovadora se presentó al inicio del negocio, pero no se desarrolló en épocas posteriores. El personal a cargo del empresario ha sido muy escaso.

Finalmente los factores externos e internos han tenido influencia en la vida de la empresa, los factores externos, fueron de mayor impacto que los internos, pero los internos sobre los cuales se tiene control, no fueron resueltos.

\section{Referencias}

Aguilar, S. y Ocampo, L. (2018). De emprendedor a empresario: iHaga que su negocio sea negocio! Ciudad de México: Patria Educación.

Aguilera, M. (2005). La economía del Departamento de Sucre: Ganadería y sector público, (63). Banco de la república. https://www.banrep.gov.co/docum/Lectura_finanzas/pdf/DTSER-63-VE.pdf

Amat, J. (2004). La continuidad de la empresa familiar. Barcelona: Gestión 2000

Arano, R., Cano M. y Olivera, D. (2012). La importancia del entorno general en las empresas. Ciencia administrativa, (2), 62-65. https://www.uv.mx/iiesca/files/2013/04/06CA201202.pdf

Bonilla, E. y Rodríguez, P. (2005). Más allá del dilema de los métodos. La investigación en ciencias sociales. (3. a ed.). Bogotá: Universidad de los Andes, Editorial Norma.

Cabanelas, J. (1997). Dirección de empresas: Bases en un entorno abierto y dinámico. Ciudad de México: Pirámide. 
Caldas, M., Reyes, C. \& Heras, A. (2009). Empresa e iniciativa emprendedora. Madrid: Editorial Editex, S.A.

Cámara de Comercio de Sincelejo (2017). Ley de transparencia. Informe económico 2017. https://ccsincelejo.org/ley-de-transparencia/\#1565708180755-ff41ff6a-5da8

Chiavenato, I. (2001). Administración. Proceso administrativo. Teoría. Proceso. Práctica. Bogotá: Mc Graw Hill.

Delgado, G. (2010). Conceptos y metodología de la investigación histórica. Revista Cubana de Salud Pública, 36 (1), 9-18. http://www.redalyc.org/articulo.oa?id=21416134003

Díaz-Bravo, L., Torruco-García, U., Martínez- Hernández, M. y Varela - Ruiz, M. (2013). La entrevista, recurso flexible y dinámico. Investigación en Educación Médica, 2(7), 162-167. https://www.redalyc.org/articulo.oa?id=349733228009

Fals, O. (2002). Historia Doble de la Costa 3. Resistencia en el San Jorge. (2. a ed.) Bogotá: Universidad Nacional de Colombia, Banco de la República y El Áncora Editores.

Fernández, M. y Campiña, G. (2010). Empresa y administración. Madrid: Editex.

Grajales, T. (2002). La metodología de la investigación histórica: una crisis compartida. Enfoques, 15(1), 4-21. http://www.redalyc.org/articulo.oa?id=25914104

Gutiérrez, R. (2013). Cincuenta años de historia. El caso del Almacén Leo de la ciudad de Sincelejo (trabajo de grado). Universidad de Sucre, Sincelejo, Colombia.

Helfat, C. y Peterefaf, M. (2009). Understanding dynamic capabilities: progress along a developmental path. Strategig Organization, 7(1), 91-102. https://doi.org/10.1177\%2F1476127008100133

Hernández, H. (2011). La gestión empresarial, un enfoque del siglo XX, desde las teorías administrativas científica, funcional, burocrática y de relaciones humanas. Escenarios, 9 (1), 38-51. https://dialnet.unirioja.es/servlet/articulo?codigo $=3875234$

Hurtado. J. (2012). Metodología de la investigación. Guía para la comprensión holística de la ciencia. Bogotá: Quirón Ediciones.

Kirzner, I. (2007). El empresario. Revista Economía y Derecho, 4(14), 113-137. http://dev.pue.itesm.mx/DoctoradoNebrija/MaterialGral/El\%20empresario.pdf

Knight, F. (1964). Risk, uncertainty and profit. New York: Sentry Press. 
Knigth, F. (1947). Riesgo, incertidumbre y beneficio. Madrid: Aguilar.

Lozano, M. (2003). Las relaciones intrafamiliares en la empresa familiar. Pensamiento \& gestión, (15), 83110. https://dialnet.unirioja.es/servlet/articulo?codigo $=2497573$

Nicolás, C. y Rubio, A. (2014). Gestión de recursos en la empresa social: un reto ineludible. Revista de

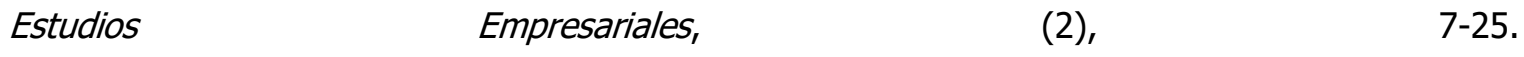
https://revistaselectronicas.ujaen.es/index.php/REE/article/view/1762

Paternina, A. (2002). Ciudad sin puertas: hechos y personajes de Sincelejo en el siglo XX. Sincelejo: Agrade.

Pérez, M. (7 de agosto de 2011). Preocupados comerciantes por las obras del centro. El Universal. https://www.eluniversal.com.co/regional/preocupados-comerciantes-por-las-obras-del-centro37194-KQEU116729

Pértuz, A. (2006). Historia empresarial de Sincelejo 1929 - 1935. Pensamiento \& Gestión, (21), 26-48. http://rcientificas.uninorte.edu.co/index.php/pensamiento/issue/view/251

Pértuz, A. (2008). Historia empresarial de Sincelejo, años 1936-1950. Búsqueca, (9), 44-64. https://revistas.unisucre.edu.co/index.php/rpg/article/view/151/177

Pértuz, A. (2015). Historia empresarial de Sincelejo 1951-1970. Pensamiento Gerencial, (3), 1-10. https://revistas.unisucre.edu.co/index.php/rpg/article/view/151

Programa de las Naciones Unidas para el Desarrollo, Corporación Universitaria del Caribe y Programa Nacional de Desarrollo Humano. (2007). El departamento de Sucre frente a los objetivos de desarrollo del Milenio. https://www.cepal.org/MDG/noticias/paginas/6/44336/Sucre_final.pdf

Puche, A. (2011). Incidencia política de la crisis del proceso 8.000 en la imagen del Partido Liberal 1994 2002. (trabajo de grado, Universidad Colegio Mayor de Nuestra Señora del Rosario). https://repository.urosario.edu.co/bitstream/handle/10336/2785/10678670862012.pdf?sequence $=1$

Quecedo, R. y Castaño, C. (2002). Introducción a la metodología de la investigación cualitativa. Revista de Psicodidáctica, (14), 1-36. https://www.redalyc.org/articulo.oa?id=17501402

Redacción El Tiempo (24 de septiembre de 1998). Cornada al presupuesto de Sincelejo. El Tiempo. Recuperado de https://www.eltiempo.com/archivo/documento/MAM-804432

Redacción El Tiempo (28 de octubre de 2009). Se proyectan doce Ciudades Amables. El Tiempo, p. 20. 
Rendón, M. (2014). La relevancia del contexto en el análisis organizacional: tradición y modernidad en una empresa familiar en Chiapas. Revista Electrónica Nova Scientia, 6 (12), 321-355. https://dialnet.unirioja.es/servlet/articulo?codigo $=4749079$

Rodríguez, M. (2004). La economía y los negocios resumen mensual 1993-2004. Bogotá: Casa Editorial El Tiempo.

Rosero, P. (2009). Los billetes, una ventana al pasado: identidad y memoria 1959 -1979. (Tesis de Maestría, Universidad Nacional de Colombia). http://bdigital.unal.edu.co/3026/

Sánchez, A. (2011). La economía del mototaxismo: el caso de Sincelejo. Documento de trabajo sobre economía regional (140). Banco de la Republica-Sucursal Cartagena. http://www.banrep.gov.co/es/contenidos/publicacion/econom-del-mototaxismo-caso-sincelejo

Schumpeter, J. (1997). Teoría del desenvolvimiento económico: Una investigación sobre ganancias, capital, crédito, interés y ciclo económico. [Traducido al español de Jesús Prados Arrarte ]. (2. a ed.). México: Editorial Fondo de Cultura Economica.

Schumpeter, J. (2012). The theory of economic development. An inquirí into profits, capital, credit, interest, and the business cycle. London: Transaction Publishers

Smith, A. (1776). Las riquezas de las naciones. [Traducido al español de Carlos Rodriguez Braun]. Madrid: Alianza Editorial Madrid.

Támara, E. (1997). Historia de Sincelejo, de los zenúes al Packing House de Coveñas. Bogotá: Impreandes Presencia S.A.

Varela, R. (2008). Innovación empresarial. Arte y ciencia de la creación de empresas. (3.a ed.). Bogotá: Pearson/Prentice Hall.

Vélez, D., Holguín, H., De La Hoz, G., Durán, J. y Gutiérrez, I. (2008). Dinámica de la empresa familiar PYME. Estudio exploratorio en Colombia. Bogotá: Fundes Internacional.

Viloria, J. (2001). Ganaderos y Comerciantes en Sincelejo, 1880-1920. Cuadernos de Historia Económica y Empresarial-Banco de la Republica (Colombia), 2-61. http://repositorio.banrep.gov.co/handle/20.500.12134/1959

Wernerfelt, B. (1984). A resource-based wiew of the firm. Strategig Managemet Journal, 5(2), $171-180$. https://www.jstor.org/stable/2486175 
Zapata, G., Mirabal, A. y Canet, M. (2015). El entorno de la organización: un estudio de sus tipologías y su vinculación con la percepción directiva y el diseño organizativo. Ciencia y Sociedad, 40(4), 785822. https://www.redalyc.org/toc. oa?id $=870 \&$ numero $=43449$ 